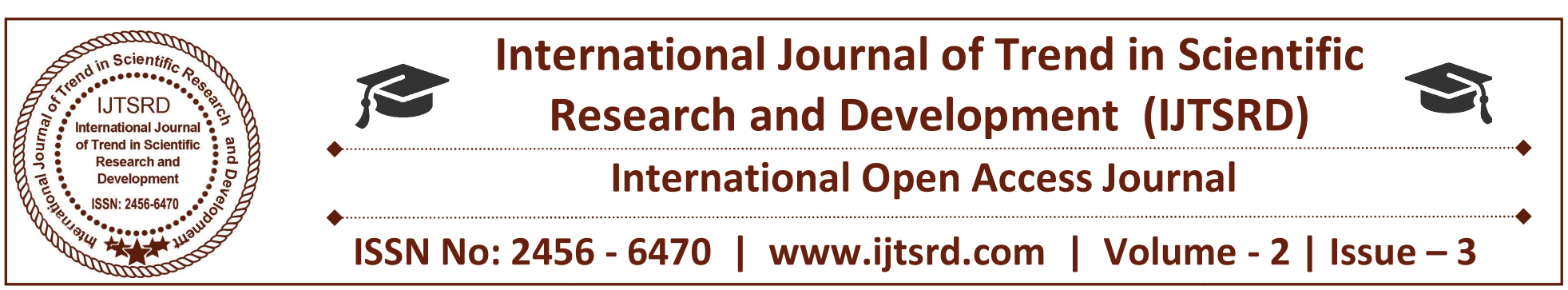

\title{
Factors Shaping Entrepreneurial Ecosystem: A Study of Gujarat State
}

\author{
Dr. Yashasvi Rajpara \\ Assistant Professor, S.G.M. (Eng. Med.) College of \\ Commerce \& Management (SEMCOM), \\ Vallabh Vidyanagar, Gujarat, India
}

\author{
Dr. Komal Mistry \\ Assistant Professor, S.G.M. (Eng. Med.) College of \\ Commerce \& Management (SEMCOM), \\ Vallabh Vidyanagar, Gujarat, India
}

\begin{abstract}
Entrepreneurial objective is a primary step to create new venture in the entrepreneurial process. Environmental conditions are one of the main factors that are strengthening or weakening intention of prospective entrepreneur. Therefore, it is important to develop conducive environment for entrepreneurship to promote entrepreneurial intention. Moreover, the promoted entrepreneurial intention will raise the rate of new venture creation. In light of the above stated facts, an attempt has been made to study factors effecting entrepreneurial environment in state of
\end{abstract} Gujarat.

In this paper, we tested the effects of five conducive entrepreneurial environments; government policies and procedures, socioeconomic conditions, entrepreneurial and business skills, financial assistance, and non-financial assistance; on the entrepreneurial intention and the comparative importance of these environmental factors.

Keywords: Entrepreneurial Ecosystem, Gujarat

\section{INTRODUCTION:}

Entrepreneurs are innovative and adaptive individuals who basically explore new opportunities and are willing to take risks involved in the change processes, (Berna, 1960). The preconceived notion of an entrepreneurship in most of the management literature highlights the risk taking abilities of an individual; however, the literature on economics totally rejects the arguments as stated in the management literature and it suggests that entrepreneurs are either risk averse or risk neutral.
Developing an entrepreneurial startup requires various forms of knowledge - even more than established companies whose structures and routines embed much of the knowledge needed for day-to-day operations (Wales, Parida and Patel, 2013). Entrepreneurs require practical, analytical and creative intelligence, which enhances the chances for success together with self-efficacy (Baum and Bird, 2010). Much of the knowledge and intelligence must come embodied in the founders of the firm to get past its initial stages, but, over time, plenty of new knowledge must be created and sourced by other means as well (Friesl, 2012). This requires a high degree of absorptive capacity from an entrepreneurial startup; without the capacity to filter and fully digest massive amounts of knowledge, the business is not able to harness whatever knowledge is at its disposal (Larrañeta, Zahra and González, 2012; Qian, Acs and Stough, 2013). In addition, managerial knowledge becomes increasingly important when the firms start to grow.

Gujarat is known for its enterprising community and industries. A part from that Gujarat has become natural choice for entrepreneurs' investor because of having friendly business climate, robust infrastructure, rich natural resources, skilled manpower \& supporting Government policies. Government has been promoting start-ups by focusing on identification of business ideas \& opportunities, supporting in networking, mentoring and incubation.

There are other stands out achievements like, 
$>$ First in Ease of Doing Business, as per Department of Industrial Policy \& Promotion (DIPP) and World Bank;

$>$ One of the top states in India for Start-ups, as per India SME Forum

$>$ Highest Investment Potential in India, as per National Council of Applied Economic Research (NCAER)

These above mentioned a fact motivates researchers to study environmental eco-system in Gujarat.

\section{LITERATURE REVIEW:}

Entrepreneurs do not act in vacuum, but react to entrepreneurial environments surrounding them (Peters \& Waterman, 1982). Entrepreneurial environments are defined as factors which are critical in developing entrepreneurship in certain regions (Gnyawali\&Fogel, 1994). Entrepreneurial environments research has focused on several frames.

For example, the research on the effect of skills and value perception shows a significant effect over the constructs (Liñán, 2008). In a study of the start-up firms in Sweden, Davidsson and Henrekson (2002) found that institutional arrangements have influence on entrepreneurial activity. The interaction between entrepreneurial environments and the development of entrepreneurship was analyzed in Hungary and presented as essential factors to develop entrepreneurship (Fogel, 2001).

Mishra \&Bal (1997) conducted an empirical study on entrepreneurial motivation in seven districts of Orissa. The author had analyzed the data collected from a sample of 110 entrepreneurs. A large number of factors-financial, institutional, cultural and political structure, overall socio-economic background, government policies, individuals' preferences and willingness-were found responsible for entrepreneurial activities in any country at any time. The behavior of human beings is controlled by their urges, drives, desires, and needs which are backed by motivational factors for entering in to entrepreneurial business. Dissatisfaction with previous job, dependency situation, insistence by elders were strong compelling factors. Among the internal and external factors, business experience and liberal financial help from financial institutions emerged as major factors. Availability of raw materials, marketing support from government, accessibility of infrastructure and technology, moral support were some of other major motivating factors.

\section{RESEARCH METHODOLOGY:}

The present study is carried out into two phaseIn the initial phase, to buildup literature framework, we have studied the existing literature on factors affecting entrepreneurship from various management and economics journals, taking into reference the Entrepreneurial Environment. This actually helps in determining major factors influencing the entrepreneurial ecosystem.

In later phase, survey is constructed based on factors concluded after literature framework. Researchers selected the western state of India, Gujarat for the study. The sample was drawn from the Gujarat state of India, as it is one of the highly industrialized states among other states, were entrepreneurial culture is well established. For this reason, student sampling is preferred in entrepreneurship research because subjects with non-entrepreneurial intention can be included in the research with subjects before an entrepreneurial process occurred (Krueger et al., 2000). In this sense, the sample of 137 Post Graduate Students of Various B-Schools in Gujarat were surveyed through questionnaire using non probability convenience sampling technique.

\section{FACTORS SHAPING ENTREPRENEURSHIP:}

The reviewed articles highlight numerous aspects of entrepreneurial ecosystems and the rise of entrepreneurship, but there are also some clearly understudied areas, a few of which will be discussed with respect to the limitations of the current study. Most importantly, nothing in the review suggests that a vibrant entrepreneurial ecosystem can be created in a top-down fashion. Entrepreneurship is a fundamentally self- motivated activity that must grow from the bottom up. It appears when people with entrepreneurial capabilities and motivation identify opportunities and the obstacles to seizing those opportunities are low. Although public intervention can support and, indeed, may often be needed to create fertile ground for entrepreneurship, direct interventions such as government funding are useful only if other factors supporting entrepreneurship are already in place. This section discusses the findings briefly in terms of five key actors, a vertical focus as a 
regional solution and the importance of product architectures.

\section{1) Government Policies and Procedures}

Governments can influence the market mechanisms and make them function efficiently by removing conditions that create market imperfections and administrative rigidities. They can also create an "enterprise culture" that enables firms to take reasonable risks and seek profits. Entrepreneurs may be discouraged to start a business if they have to follow many rules and procedural requirements, if they have to report to many institutions, and if they have to spend more time and money in fulfilling the procedural requirements.

Governments typically try to encourage entrepreneurship by direct interventions, such as funding, as well as indirectly by creating a productive ground for innovation with varying results (Kasabov, 2015; Lin, Chang and Shen, 2010; Nathan and Vendore, 2014). For instance, maintaining a strong regional knowledge ecosystem (e.g., universities) can be tremendously helpful but does not automatically generate business ecosystems and entrepreneurship (Clarysse, Wright, Bruneel and Mahajan, 2014). Highly developed financial markets foster innovation, whereas tight product and labor market regulation tends to obstruct the regional capacity to innovate (Barbosa and Faria, 2011). Sometimes, government championing and regulatory protection of a disruptive innovation can be more effective than direct subsidies and funding in promoting entrepreneurship (Caerteling, Halman, Song, Dorée and Van Der Bij, 2013; Pinkse, Bohnsack and Kolk, 2014).

\section{2) Socioeconomic Conditions}

Entrepreneurship may not prosper if most members of the society view it with doubt. A favorable attitude of the society toward entrepreneurship and an extensive public support for entrepreneurial activities are both needed to motivate people to start a new business. In fact, social factors may be equally important as availability of loans, technical assistance, physical facilities, and information.

Entrepreneurship is not an occupation. It becomes a part of founder's personal identity and passion. A possible future self as an entrepreneur is one of the motivators forcreating a startup company (Farmer, Yao and Kung-Mcintyre, 2011). Many of the positive entrepreneurial personality traits, such as energy, self- confidence, ambition and independence, can also degenerate into aggressiveness, narcissism, ruthlessness and irresponsibility (Miller, 2015). When entering specific innovation ecosystems, entrepreneurs should consider whether their personality and skills fit with the demands of the particular environment (Nambisan and Baron, 2013).

\section{3) Entrepreneurial and Business Skills}

A low level of technical and business skills could stop motivated entrepreneurs from starting a new venture (Davidsson, 1991; Vesper, 1990). Similarly, unless entrepreneurs are well equipped with technical and business skills, they may not be able to overcome various problems they encounter at different stages of their business development. The need for training programs appears greater in countries where very limited external assistance is available, market imperfections exist, large industries dominate the industrial sector, government policies do not support small businesses, and several bureaucratic hurdles have to be overcome to get permission to start a business.

Entrepreneurs require practical, analytical and creative intelligence, which enhances the chances for success together with self-efficacy (Baum and Bird, 2010). Much of the knowledge and intelligence must come embodied in the founders of the firm to get past its initial stages, but, over time, plenty of new knowledge must be created and sourced by other means as well (Friesl, 2012). Relevant new knowledge and learning may relate, for instance, to understanding strategic options in an uncertain and changing environment (Fernhaber and Patel, 2012; Larrañeta, Zahra and González, 2012).

\section{4) Financial Support to Businesses}

Generally, entrepreneurs require financial assistance for at least one of three purposes: to diversify or spread the start-up risk, to accumulate start-up capital, and to finance growth and expansion. Funding and ownership structures are vital to new firm creation and entrepreneurial performance. Without the right motivational structures and adequate funding that matches the ambitions and competitive background of the venture, it is difficult to launch a company to a successful path. Personal wealth plays a role in the founder's ability to take an appropriate level of risk and to remain motivated in the face of difficulty. While financial slack allows founders to take adequate personal risks, having too much personal 
founder wealth tends to decrease venture performance (Hvide and Møen, 2010). There are four types of funding: independent venture capital, corporate venture capital, angel investments and public government funding.

\section{5) Non-financial Support to Businesses}

Entrepreneurs need support services in addition to financial assistance. In particular, entrepreneurs need most assistance in conducting market studies, in preparing business plans, and in getting loans. Business incubators plays important role by providing variety of services to the budding entrepreneurs.

Table1: A framework for entrepreneurial environments (Gnyawali \& Fogel, 1994)

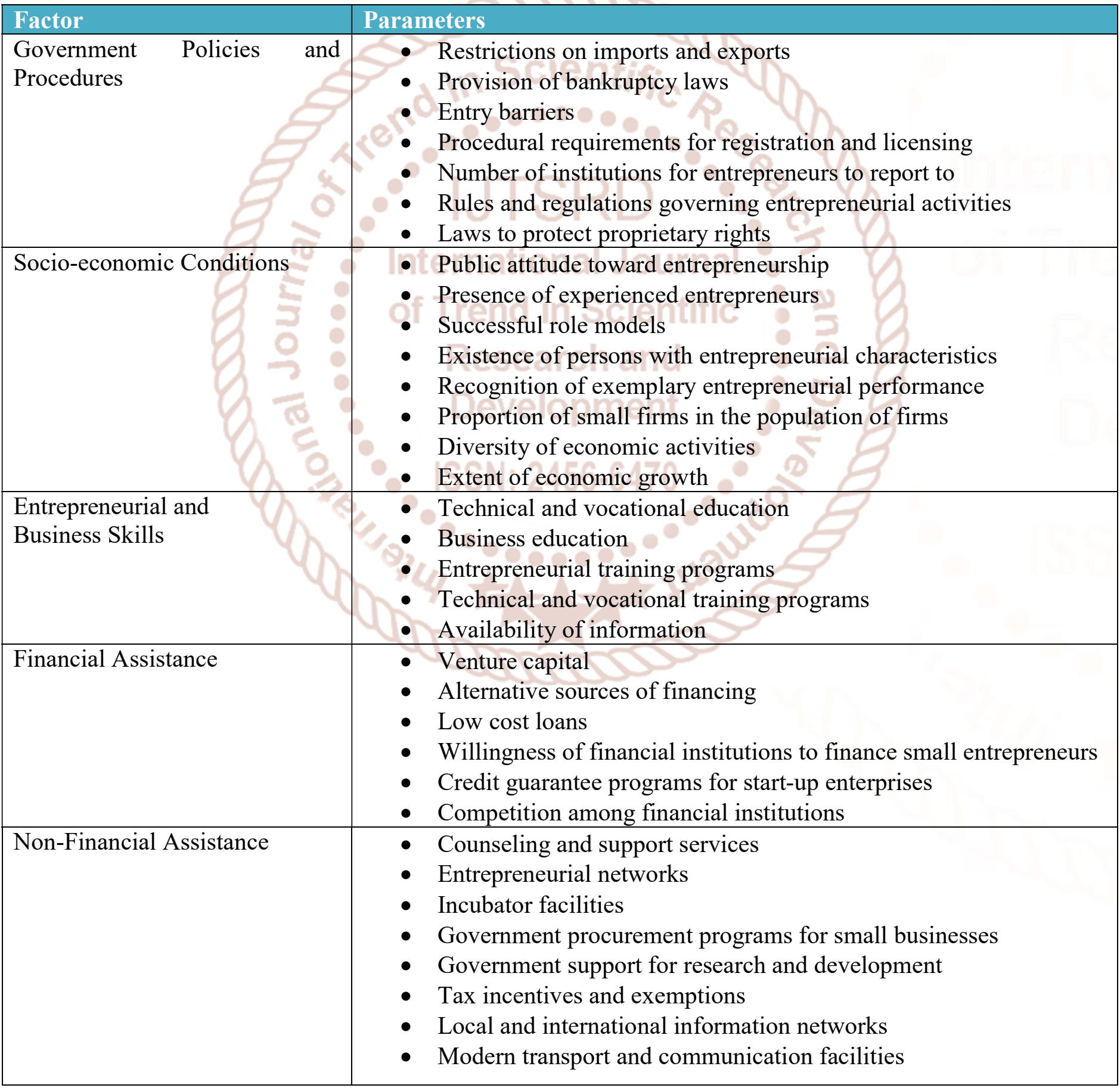


International Journal of Trend in Scientific Research and Development (IJTSRD) ISSN: 2456-6470

\section{LITERATURE OUTPUT:}

On the primary basis of results of research by Gnyawali \& Fogel (1994), it is found that five environmental factors Government Policies and Procedures, Entrepreneurial and Business Skills, Socioeconomic Conditions, Financial Assistance, and Non-Financial Assistance are framing environmental ecosystem.

Based on the literature review, all of the five environmental factors will have positive effects on the entrepreneurial intention. From this foundation, the following hypothesis is offered:
H1: There is the optimum comparative importance of five dimensions of Entrepreneurial Environments, which is the most conducive to the Entrepreneurial Intention.

On the basis of in depth literature study, researchers have found that all environment factors judged important by various authors under their own research framework, however under majority of research work, researchers have identified socioeconomic condition is the most influenced factor to develop entrepreneurial intention. With influence of this researchers have intended to conduct survey in the state of Gujarat for which following results have been obtained.

\section{Analysis of Comparative Importance of Five Factors based on Primary Data:}

Table 2: Characteristics of the Sample

\begin{tabular}{|l|l|}
\hline Demographics & Frequency \\
\hline Gender & 99 (Male), 38(Female) \\
\hline $\begin{array}{l}\text { Education } \\
\text { Level(Father) }\end{array}$ & 4 (Primary), 5 (SSC), 50 (HSC), 65 (Graduate), 13 (other) \\
\hline $\begin{array}{l}\text { Education } \\
\text { level(Mother) }\end{array}$ & 4 (Primary), 7 (SSC), 77 (HSC), 43 (Graduate), 5 (other) \\
\hline $\begin{array}{l}\text { Occupation(Father) } \\
\text { Total Yearly } \\
\text { Family Income }\end{array}$ & $\begin{array}{l}44 \text { (Private sector employee), 17 (Public sector employee), } \\
54 \text { (self-employed), 2 (retired), 2 (unemployed), 18(other) }\end{array}$ \\
\hline
\end{tabular}

Table 2 displays 99 students (72.26\%) were male, while 38 (27.74\%) were female. Looking into educational level of the father, highest proportion is found with Graduate $(47.44 \%)$ and for mother, HSC $(56.20 \%)$ is the highest in the category. The father's occupation of self-employed $(39.42 \%)$ was the highest category, while total family income under Rs.8,00,000 was $80.29 \%$.

Table 3: Comparative Important rank of Factors Shaping Entrepreneurial Environments

\begin{tabular}{|l|l|l|}
\hline Factor & Rank & W.A.M \\
\hline Government policies and procedures & 3 & 3.62 \\
\hline Socioeconomic conditions & 1 & 5.67 \\
\hline Entrepreneurial and business skills & 4 & 2.96 \\
\hline Financial assistance & 2 & 4.89 \\
\hline Non-financial assistance & 5 & 1.84 \\
\hline
\end{tabular}


The comparative importance of attributes is shown in Table3in the order from more important to less important; socioeconomic conditions (5.67), financial assistance (4.89), government policies and procedures (3.62), entrepreneurial and business skills (2.96), and non - financial assistance (1.84).

\section{Table 4: Gender wise Comparative importance score of environmental factors}

\begin{tabular}{|l|l|l|}
\hline Factor & Male $(\mathrm{N}=99)$ & Female (N=38) \\
\hline Government policies and procedures & $21.431 \%$ & $24.410 \%$ \\
\hline Socioeconomic conditions & $25.531 \%$ & $25.855 \%$ \\
\hline Entrepreneurial and business skills & $15.766 \%$ & $14.588 \%$ \\
\hline Financial assistance & $23.668 \%$ & $23.929 \%$ \\
\hline Non-financial assistance & $13.604 \%$ & $11.218 \%$ \\
\hline
\end{tabular}

Both male and female students weighed most on socioeconomic conditions. While government policies and procedures are the second important factors for male students, financial assistance is considered as the second for female students.

\section{Table 5: Father's Occupation Wise Comparative importance score of environmental factors}

\begin{tabular}{|l|l|l|}
\hline Factor & $\begin{array}{l}\text { Employed father } \\
(\mathbf{N}=61)\end{array}$ & $\begin{array}{l}\text { Self-employed } \\
\text { father (N=53) }\end{array}$ \\
\hline Government policies and procedures & $18.455 \%$ & $27.569 \%$ \\
\hline Socioeconomic conditions & $21.902 \%$ & $27.026 \%$ \\
\hline Entrepreneurial and business skills & $18.098 \% 6=6470$ & $12.987 \%$ \\
\hline Financial assistance & $26.895 \%$ & $20.448 \%$ \\
\hline Non-financial assistance & $14.651 \%$ & $11.970 \%$ \\
\hline
\end{tabular}

Table 5 represents the comparative importance of entrepreneurial environments between students with employed father and students with self-employed father. Financial assistance is the most important factor for students with employed father. However, students with self-employed father put an importance on government policies and procedures slightly more than on socioeconomic conditions.

\section{Findings \& Conclusion:}

All the environmental factors showed significant effects on elevating entrepreneurial intention. Somewhat surprisingly, socioeconomic conditions were the most conducive factor rather than financial assistance in promoting entrepreneurial intention. Maybe this is because Gujarati emphasize group culture most of all.

The comparative importance of attributes is shown in Table 3 in the order from more important to less important; socioeconomic conditions (5.67), financial assistance (4.89), government policies and procedures (3.62), entrepreneurial and business skills (2.96), and non - financial assistance (1.84).

On the basis of literature framework as well as primary survey it is clear that for entrepreneurial intentions, all factors are important. However, 
socioeconomic conditions plays major role. In this study, researchers have selected students with motive of non-entrepreneurial intentions, even at that state also socioeconomic conditions, is most powerful factor in construction of entrepreneurial intentions.

With the recently launched Student Startup and Innovation Policy of Government of Gujarat, we were able to bake in most of our learning over the last five years or so at the policy level, and institutionalize a) university-driven pre-incubation support, b) interventions to develop a culture of innovation and entrepreneurship without the fear of failure, c) incentives for all stakeholders at the pre-incubation layer such as students, academicians, administrators, mentors, investors, and other ecosystem stakeholders, and, d) micro-funding mechanisms for funding student-led ideas, as well as fund for pre-incubation support systems through educational machinery.

It now remains to be seen how quickly policymakers around the country are able to address the need of support for student entrepreneurship and how well such policies are executed. It goes without saying that the startup ecosystem of the country, thanks to strong city-centered ecosystems, is growing at a swift pace, and with receptive and responsive governments at the helm, the scenario appears bright for startups in India.

\section{REFERENCES:}

1. Aaltonen, A (2017). Factors Shaping Entrepreneurial Ecosystems and the Rise of Entrepreneurship: A View from Top Management Journals. Demos Helsinki Working Paper.

2. Aernoudt, R. (2004). Incubators: Tool for entrepreneurship?. Small Business Economics, 23(2).,pp.127-135.

3. Allen, D., \& Rahman, S. (1985). Small business incubators: A positive environment for entrepreneurship. Journal of Small Business Management, 23(3), pp. 12-22.

4. Baum, J. R. and Bird, B. J. (2010). The successful intelligence of high-growth entrepreneurs: links to new venture growth. Organization Science, 21(2), pp. 397-412.

5. Barbosa, N. and Faria, A. P. (2011). Innovation across Europe: how important are institutional differences? Research Policy, 40(9), pp. 11571169.
6. Berna, James G., 1960 Industrial Entrepreneurship in Madras State, Bombay: Asia Publishing House

7. Caerteling, J. S., Halman, J. I. M., Song, M., Dorée, A. G. and Van Der Bij, H. (2013). How relevant is government championing behavior in technology development? Journal of Product Innovation Manage- ment, 30(2), pp. 349-363.

8. Clarysse, B., Wright, M., Bruneel, J. and Mahajan, A. (2014). Creating value in ecosystems: crossing the chasm between knowledge and business ecosystems. Research Policy, 43(7), pp. 11641176.

9. Davidsson, P. (1991), Continued entrepreneurship: Ability, need, and opportunity as determinants of small firm growth. Journal of Business Venturing, 6. 405-429.

10. Davidsson, P., \&Henrekson, M. (2002).Determinants of the prevalence of start-ups and high-growth firms.Small Business Economics, 19(2), pp.81.

11. Farmer, S. M., Yao, X. and Kung-Mcintyre, K. (2011). The behavioral impact of entrepreneur identity aspiration and prior entrepreneurial experience. Entrepreneurship Theory \& Practice, 35(2), pp. 245-273.

12. Fernhaber, S. A. and Patel, P. C. (2012). How do young firms manage product portfolio complexity? The role of absorptive capacity and ambidexterity. Strategic Management Journal, 33(13), pp. 1516-1539.

13. Fogel, G. (2001). An analysis of entrepreneurial environment and enterprise development in Hungary .Journal of Small Business Management, 39(1), pp.103-109.

14. Friesl, M. (2012). Knowledge acquisition strategies and company performance in young high technology companies. British Journal of Management, 23(3), pp. 325-343.

15. Gnyawali, D., \&Fogel, D. (1994).Environments for entrepreneurship development: Key dimensions and research implications. Entrepreneurship: Theory \& Practice, 18(4), 4362.

16. Hvide, H. K. and Møen, J. (2010). Lean and hungry or fat and content? Entrepreneurs' wealth and start- up performance. Management Science, 56(8), pp. 1242-1258. 
17. Kasabov, E. (2015). Start-up difficulties in earlystage peripheral clusters: the case of IT in an emerging economy. Entrepreneurship Theory \& Practice, 39(4), pp. 727-761.

18. Larrañeta, B. Zahra, S. A. and González, J. L. G. (2012). Enriching strategic variety in new ventures through external knowledge. Journal of Business Venturing, 27(4), pp. 401-413.

19. Lee, B. (2010). University students' assessment of entrepreneurial environments. University of Nebraska - Lincoln.

20. Lin, G. T.-R., Chang, Y.-H. and Shen, Y.-C. (2010). Innovation policy analysis and learning: comparing Ireland and Taiwan. Entrepreneurship \& Regional Development: An International Journal, 22(7-8), pp. 731-762.

21. Liñán, F. (2008). Skill and value perceptions: How do they affect entrepreneurial intentions?.International Entrepreneurship and Management Journal, 4(3), pp.257- 272.

22. Miller, D. (2015). A downside to the entrepreneurial personality? Entrepreneurship Theory and Practice, 39(1), pp. 1-8.

23. Mishra,B.B. and K.Bal (1997). "Women Entrepreneurs in Orissa,A study of their Profile, Motivation and constraints", Indian Journal of Commerce.1.193,part 4:385

24. Nambisan, S. and Baron, R. A. (2013). Entrepreneurship in innovation ecosystems: entrepreneurs' self-regulatory processes and their implications for new venture success. Entrepreneurship Theory and Practice, 37(5), pp. 1071-1097.

25. Nathan, M. and Vendore, E. (2014). Here be startups: exploring London's 'Tech City' digital cluster. 46(10), pp. 2283-2299.

26. Rajpara, Y. and Patel, M. (2014). A Study on Risk Taking Propensity among Indian Entrepreneurs Case of Gujarat. KSV-JHSSM Journal of Humanities, Social Science \& Management, 5(1).pp. 119-126.

27. Vesper, K. H. (1990). New venture strategies. Englewood Cliffs, NJ; Prentice Hall.

28. Wales, W. J., Parida, V. and Patel, P. C. (2013). Too much of a good thing? Absorptive capacity, firm performance, and the moderating role of entrepreneurial orientation. Strategic Management Journal, 34(5), pp. 622-633.

\section{Web Reference:}

1. https://yourstory.com/2017/01/india-startup-gamebolstering-student-entrepreneurship/ (accessed on $11^{\text {th }}$ February, 2018) 